\title{
User's Expectations on Interactive Travel Guide eBook: A Case Study
}

\author{
L. S., Lee ${ }^{1}$, S. S., Shaharuddin ${ }^{2}$, G. W. Ng ${ }^{3}$, S., Wan-Busrah ${ }^{4}$ \\ ${ }^{1}$ Faculty of Creative Arts and Design, Universiti Malaysia Sarawak \\ 94300 Kota Samarahan, Sarawak, Malaysia \\ ${ }^{1} 15020176$ esiswa. unimas.my \\ ${ }^{2}$ ssshukhailalfaca.unimas.my \\ ${ }^{4}$ syaryfah@faca.unimas.my \\ ${ }^{3}$ Faculty of Cognitive Sciences and Human Development, Universiti Malaysia Sarawak \\ 94300 Kota Samarahan, Sarawak, Malaysia \\ ${ }^{3}$ gwngefes . unimas.my
}

\begin{abstract}
The use of modern interactive travel guide eBook is becoming a necessity of many destinations to stay competitive and attractive to the modern tourist. The aim of this paper is to study users' expectations for the development of a mobile travel guide eBook/ book app. Hence, an experimental investigation was conducted to explore and determine users' demand of acceptance - the requirements and expectations of interactive multimedia features content to bring travel guide eBook to life with video, audio and other interactive features in an engaging way. This study uses primary data analysis from 128 respondents who were randomly chosen in Malaysia and some other countries. A preliminary survey, based on online questionnaires and brainstorming sessions were conducted to identify the influential of users' perception towards features content requirements and expectations prerequisite. Analysing reliability and validity factor has been conducted to further support users' acceptance of travel guide eBook technology revolution. Findings show that there is a significantly high level of potential demand of merging graphic design and interactive multimedia features being implemented in an attractive and meaningful way in the tourism industry.
\end{abstract}

Keywords - Interactive, features, enhance, user expectation, travel guide eBook

\section{INTRODUCTION}

Recently, a study by [1] found that the implications of the Internet and other growing interactive multimedia platforms for tourism promotion are far reaching. As we enter a new era, the Information Age, destination marketing organizations and other major providers of tourism services need to understand both the Internet and the other emerging interactive technologies, their increasing use by tourists and travellers and how to capitalize on these new channels. It is a multimedia experience. This must be comprehensive, held in electronic formats, and needs to be constantly verified and updated.

Although there were many studies about Internet travel guide, few of them focused on multimedia travel guide eBook or book app. Multimedia that is being delivered in a variety of formats and these media are becoming increasingly used to provide a rich audio-visual experience contents. Hence, upon this rationale, a case study approach was adopted with an objective to consider the basis requirements of interactive multimedia components required and expected by traveller and potential travel guide eBook user. Understanding the state-of-the-art technologies multimedia features/elements like audio, video, animation, slideshows, Augmented Reality $360^{\circ} / 3 \mathrm{D}$ model, Virtual Reality/panoramic scene, hyperlinks, email, geolocation/map, zoomable image, vertical scrolling text, search engine, and bookmark could help to bring added value into travel guide eBook. Hence, this paper raises the need to identify the type of features/elements requires as variables in this study. Fig. 1 shows the type of multimedia elements from multimedia authoring resource [2].

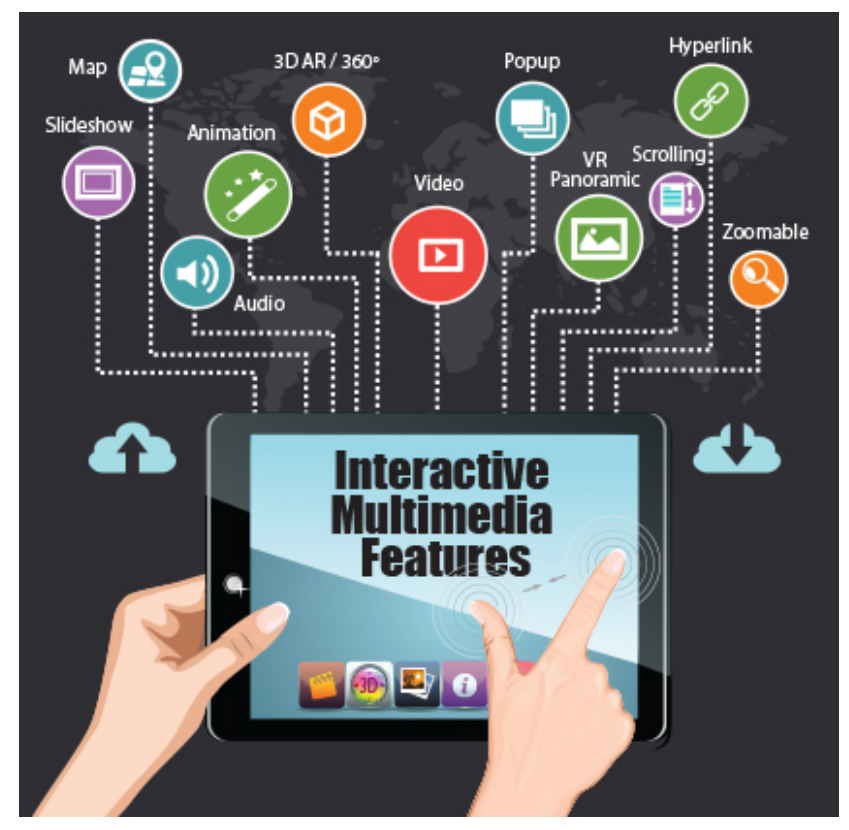

Fig. 1 Component of multi-rich interactive eBook

The evolution of the travel guide eBook represents a significant new development, chiefly because it's potential to offer added value to the current existing format to enable user gain a better understanding knowledge of travel guides 